\title{
Courting controversy
}

Suzanne J Farley

People love a good argument. Some as combatant, many as voyeurs. Physicians and scientists are no different. Indeed, frank exchange of opinions is essential to efficient medical and scientific progress. If journals are to promote such advancement they must truly reflect the concerns of their audiences by tackling controversial issues.

Covering such 'hot potatoes' can, however, present problems to journal editors. It can be difficult to distinguish an adequately supported opinion from an unduly biased assertion. Peer review is an essential tool that journal editors use to help them decide where the fine line between the two lies.

Thankfully, in most instances, a consensus emerges among peer reviewers. Accept, reject, or revise. In some fields, however, a paper judged by one peer reviewer to contain well-supported opinions will be branded a biased advertorial by another. Soliciting feedback from a greater number of peer reviewers might solve the problem. But what happens in the rare instances when consensus cannot be reached?

The easiest option is to reject the manuscript. Editors should, however, give careful consideration to what the lack of consensus among peer reviewers really indicates. If the peer reviewers have been selected correctly, taking into account expertise, experience and potential conflicts of interest, then widely disparate feedback is probably an indicator of the topic being controversial, rather than of the manuscript being of poor quality. Rejection of the paper could stifle an important debate.

At Nature Clinical Practice Nephrology, we strive to promote, rather than stifle, exchanges of opinion that could potentially change the way nephrologists manage their patients. In every issue we publish at least one Viewpoint. These articles are two-page forums in which expert authors share their opinion on any

\section{By giving proponents on both sides of the issue the opportunity to present their views, we hope to accurately reflect the diversity of opinion in the wider community}

SJ Farley is Editor of Nature Clinical Practice Nephrology.

\section{Competing interests}

The author declared she has no competing interests.

www.nature.com/clinicalpractice doi:10.1038/ncpneph0194 topic of relevance to practicing nephrologists. Viewpoints are peer reviewed to ensure that the opinions expressed are supported by sufficient evidence and backed up by weight of experience. When our advisors feel that a particular issue justifies a pro/con format, two Viewpoints can be commissioned on the same topic.

In some instances, however, authors cannot adequately formulate their arguments in two short pages. So, as in this issue of the journal, we commission a series of short Reviews. Our series on management of secondary hyperparathyroidism in chronic kidney disease begins on page 316 , with a balanced overview of the renal indications of calcimimetics.

The first-in-class calcimimetic cinacalcet (Sensipar ${ }^{\circledR} /$ Mimpara $^{\circledR}$, Amgen Inc., Thousand Oaks, CA) was approved in 2004 in the US and Europe for treatment of secondary hyperparathyroidism in dialysis patients. Approval of cinacalcet, and emergence of new data on other treatments for perturbed mineral metabolism, postdated formulation of the latest National Kidney Foundation's Kidney Disease Outcomes Quality Initiative (NKF-K/DOQI) guidelines. Some practitioners-represented here by Albert Fournier and co-workers on page 326 - contend that these new data should spur re-appraisal of the guidelines. Others, like Glenn Chertow and colleagues (page 337), assert that current recommendations should not be modified until more trials are conducted.

By giving proponents on both sides of the issue the opportunity to present their views, we hope to accurately reflect the diversity of opinion in the wider community of practicing nephrologists. This is not a neat solution. But the alternative-publishing a single article containing clear-cut guidance-would have been a potentially dangerous misrepresentation of this important clinical conundrum. 